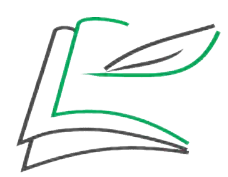

Entretextos

\title{
Incorporando às sequências didáticas no ensino básico a análise de memes trazendo sentenças anômalas -em desobediência à seleção semântica
}

\author{
Incorporando en secuencias didácticas para la educación básica el análisis \\ de memes con oraciones anómalas - que rompen la selección semántica
}

\author{
Incorporating into didactic sequences for basic education the exam of \\ memes within semantic anomaly - not satisfying semantic selection
}

\author{
Daví Lopes Franco ${ }^{1}$ (iD) https://orcid.org/0000-0001-6669-6192 \\ Ana Paula Quadros Gomes ${ }^{2}$ (iD https://orcid.org/0000-0002-3476-0193
}

\begin{abstract}
RESUMO: O presente artigo reporta atividades didático-pedagógicas que tomam como premissas hipóteses da semântica formal, como a seleção semântica e a gramática interna dos falantes. A partir de um estudo de caso de livros didáticos e da nossa vivência como professores, percebemos que sentenças anômalas e seleção semântica não são temas articulados nem discutidos na escola. Para preencher essa lacuna, desenhamos atividades de interpretação de memes, executadas com alunos do 70 ano do ensino fundamental. Verificamos que o aluno é capaz de interpretar sentenças anômalas a partir de seus conhecimentos inerentes e de reconhecer a ironia e o humor produzidos pela anomalia em memes. Oferecemos a descrição dessas atividades como contribuição a educadores interessados em práticas discursivas textuais, associadas ao conhecimento inerente de gramática do falante. Apresentamos um plano de atividades com o uso de memes, detalhando os conhecimentos trabalhados na experiência. Esta proposta é um tijolinho na construção de uma educação linguística mais crítica e reflexiva.
\end{abstract}

PALAVRAS-CHAVE: Semântica. Ensino. Interação.

ABSTRACT: This article presents some didactic-pedagogical activities. Their premises are hypotheses from formal semantics, such as semantic selection, and the inner grammar of speakers. After taking a textbook for a case study, and based on our experience as teachers, we realized that anomalous sentences and semantic selection are not being discussed at schools. To fill this gap, we designed some meme interpretation activities, carried out with $7^{\text {th }}$ grade elementary school students. We found that a student can interpret anomalous sentences

\footnotetext{
${ }^{1}$ Mestrando em Letras Vernáculas (Língua Portuguesa), pela Universidade Federal do Rio de Janeiro. Professor de Língua Portuguesa e Redação em turmas de ensino básico. E-mail: davi.franco@letras.ufrj.br

2 Pós-doutorado no Departamento de Letras Clássicas e Vernáculas da Universidade de São Paulo (USP) Professora da Faculdade de Letras da Universidade Federal do Rio de Janeiro (LEV/FL/UFRJ). E-mail: anaquadrosgomes@letras.ufri.br
} 
Franco, D. L.; Gomes, A. P. Q.

based on his/her inner language knowledge and simultaneously recognize the irony and humor produced by anomaly in memes. We describe these activities as a contribution to educators who are interested in textual discursive practices in association with the speaker's inherent knowledge of grammar. In this article, we present in detail some activity plans using memes. Hopefully, this proposal may be a brick in the construction of a more critical and reflective language education.

KEYWORDS: Semantics. Teaching. Interaction.

RESUMEN: El presente artículo informa sobre las actividades didáctico-pedagógicas que tienen como premisas las hipótesis de la semántica formal, como la selección semántica y la gramática interna de los hablantes. A partir de un estudio de caso de un libro didáctico y nuestra experiencia como docentes, notamos que las oraciones anómalas y la selección semántica no se articulan o discuten en la escuela. Para llenar este vacío, ilustramos actividades de interpretación de memes, utilizadas con alumnos de primaria de 70 grado. Notamos que el alumno es capaz de interpretar las oraciones anómalas basadas en su conocimiento inherente y reconocer la ironía y el humor producidos por la anomalía en los memes. Ofrecemos la descripción de estas actividades como una contribución a los educadores interesados en las prácticas discursivas textuales, asociadas con el conocimiento inherente de la gramática del hablante. Presentamos un plan de actividades con el uso de memes, que detalla el conocimiento trabajado en la experiencia. Esta pesquisa es una pequeña propuesta para una construcción de una educación lingüística más crítica y reflexiva.

PALABRAS CLAVE: Semántica. Docencia. Interacción

\section{Introdução ${ }^{3}$}

Apresentamos aqui uma proposta produzida para integrar uma sequência de atividades didáticas, para aulas de língua portuguesa da sétima série do fundamental, e discutimos o alcance dessa prática educacional. O conjunto de atividades que propomos aproveita a intuição dos falantes sobre o fenômeno da anomalia semântica e versa sobre um fenômeno semântico que não vinha recebendo muita atenção em sala de aula, sobretudo no âmbito do ensino básico: a seleção semântica (doravante s-seleção), e sua contraparte, a anomalia semântica. Entendemos por seleção semântica a seleção de argumentos por parte do seu predicador, segundo certas propriedades semânticas. Por exemplo, o português tem diversos verbos de ingestão de alimentos, como "comer", "beber" e "tomar". Esses predicadores selecionam propriedades semânticas de seu argumento externo: que esteja vivo, alimente-se por boca e tenha aparelho digestivo. Tais exigências estão satisfeitas em "O gato tomou leite". O que torna estranha a sentença \#"A parede tomou leite" ${ }^{4}$, é o fato de o argumento "a parede" não atender às exigências semânticas do predicador que o seleciona. Do ponto de vista sintático, as

\footnotetext{
${ }^{3}$ Agradecemos aos pareceristas anônimos por suas importantes contribuições para o aprimoramento deste artigo. Naturalmente, todos os erros são de nossa inteira responsabilidade.

${ }^{4}$ O símbolo \# significa anomalia semântica, ou seja, estranheza, ou a ausência de alguma interpretação particular para a sentença em exame.
} 
exigências do predicador estão plenamente atendidas: o verbo "tomar" pede dois argumentos, exatamente o número de argumentos nessa sentença; ambos são de categoria nominal, o que está de acordo com as especificações de "tomar", que, diferentemente de verbos como "dizer" (como, p. ex., em "Pedro disse que viria"), não aceita complementos oracionais (*"O gato tomou que estava bom") ${ }^{5}$. Então, em \# "A parede tomou leite", as exigências sintáticas estão atendidas, mas as semânticas não. 0 resultado não é agramaticalidade, mas anomalia semântica. Como nos diz Roberta Pires de Oliveira,

"Há, na verdade, diferentes formas de agramaticalidade, de violação do sistema e nem todas têm o mesmo funcionamento, como mostra Chomsky ao distinguir gramaticalidade de aceitabilidade. Sentenças bem formadas sintaticamente podem ser semanticamente anômalas". (OLIVEIRA, 2010, p. 13)

Sentenças com anomalia semântica também são rotuladas de absurdas, incoerentes ou de significado pouco usual. O exemplo mais famoso de anomalia semântica é de Chomsky (1957), originalmente em inglês: "Ideias verdes incolores dormem furiosamente". Essa sentença traz argumentos em número e categoria corretos. Porém, como não têm superfície, ideias não podem refletir a luz, nem ter cor; daí "ideias verdes" ser um absurdo. Algo verde não pode ser incolor, daí termos contradição em "ideias verdes incolores". O predicador "dormir" pede um único argumento, com as propriedades de ser vivo e passar por ciclos de sono; "ideias" não satisfazem essa $s$ seleção. Um verbo intransitivo pode der modificado, como em "dormir tranquilamente", mas "furiosamente" não é um modificador adequado para um evento de "dormir", representando nova anomalia. Chomsky usou seu famoso exemplo para mostrar que, embora semântica e sintaxe estejam imbricadas em objetos linguísticos, elas podem ser separadas. É possível montar uma sentença obedecendo a todos os preceitos da boa combinação sintática sem que a seleção semântica seja respeitada. 0 contrário também é possível. Um exemplo de não-obediência aos princípios da sintaxe, em que há respeito à s-seleção, é *"A molar está chorona com uma dente no cárie criança" (vemos que os mesmos elementos formariam uma boa sentença na ordem "A criança chorona está com uma cárie no dente molar"). Além de mostrar que é possível isolar propriedades sintáticas

\footnotetext{
${ }^{5} \mathrm{O}$ asterisco na última sentença indica violação de regras sintáticas, que incluem não dar o número certo de argumentos para o predicado e também dar ao predicado um argumento de natureza categorial diferente da exigida.
} 
de propriedade semânticas, Chomsky também apontou que sentenças agramaticais são improcessáveis, ou seja, não fazem parte da gramática da língua, não podendo, por isso, ser interpretadas de modo algum pelos falantes. Sentenças anômalas, por outro lado, apresentam significado, mas incomum, inusitado, poético, metafórico, irônico etc. Interessantemente, o próprio exemplo clássico de anomalia criado por Chomsky tornouse parte de um poema de Haroldo de Campos (1984).

Uma vez que sentenças anômalas obedecem às regras linguísticas o suficiente para serem processadas pelo falante, mesmo desobedecendo à seleção semântica, sendo interpretáveis, mas só de forma incomum, inusitada, elas são um recurso expressivo muito interessante para a ironia, o humor ou a poesia. Ao estarem no limite da interpretabilidade, em termos de boa composição linguística, as sentenças anômalas requerem de seu ouvinte ou leitor um esforço extra: que seja cooperativo, ao tentar extrair algum sentido de uma sentença não-padrão. Sua interpretação requer imaginação, uma busca de sentido para além das margens coibidoras das regras semânticas ordinárias. Nesse sentido, sentenças anômalas "sacodem" a mesmice da linguagem, levando os falantes a refletirem sobre possibilidades expressivas oferecidas pela sua língua. Na busca de conferir sentido a uma sentença anômala, o falante se torna mais consciente das regras de seleção semântica que usa automaticamente na sua fala e escrita diárias. A estranheza de sequências como "ideias verdes incolores" faz refletir sobre o fato semântico de que, ordinariamente, um mesmo objeto não pode ser colorido e também incolor, e que abstrações como ideias não podem apresentar cores. Ao interpretar anomalias como "ideias verdes incolores", o falante precisa abandonar a seleção semântica padrão e buscar alternativas criativas, considerando, por exemplo, que o termo descreva ideias ainda não amadurecidas (daí estarem verdes) e que não aderiram a nenhuma bandeira ideológica específica ainda (daí serem incolores).

Levando isso em conta, nos ocorreu que as sentenças anômalas, presentes em gêneros em que a ironia, o humor ou a poesia são destaque, poderiam trazer à tona inúmeras possibilidades de criatividade linguística e vir a ser uma poderosa ferramenta de reflexão os conhecimentos inatos sobre a língua materna, nas aulas de língua portuguesa do ensino fundamental. Em que pese o fato de não ser preciso instruir nenhum falante sobre a gramática de sua língua nativa, uma vez que a escola ensina gramática, tanto aproveitar o conhecimento inato sobre suas regras quanto colocar em foco os efeitos 
estilísticos da quebra parcial de regras dessa mesma gramática vão encorajar a exploração estilística e estimular a criatividade linguística.

Não obstante, verificamos que o fenômeno da seleção semântica (com sua contraparte, a anomalia semântica) não é sequer mencionado nas Diretrizes Curriculares Nacionais da Educação Básica. A nosso ver, malgrado o fato de a seleção semântica ser parte do conhecimento inconsciente do falante sobre a gramática de sua própria língua, os livros didáticos bem poderiam trazer para um benéfico e produtivo debate alguns exemplos de anomalia semântica em uso. Para nos certificarmos da ausência de abordagens sobre a anomalia em obras didáticas, examinamos, como amostragem, 0 livro didático "Projeto Araribá Plus - Português 70 Ano" (JACINTHO, 2018). Fomos verificar se havia esse conteúdo e como seria abordado. Esse livro foi escolhido por ser adotado no Colégio e Curso Sonnart ${ }^{6}$, onde foram aplicadas as atividades cujos resultados trazemos neste trabalho.

Valendo-nos do arcabouço teórico da semântica formal, conforme apresentado em manuais de semântica como os de Quadros e Mendes (2018), Oliveira (2012) e Cançado (2003, 2008), investigamos a intuição dos alunos quanto ao fenômeno em análise. Comprovamos que, mesmo sem terem tido instrução formal sobre tais fenômenos, os falantes naturalmente reconhecem sentenças anômalas e as interpretam nos textos, explorando suas nuances de significados.

Este trabalho se justifica também em decorrência de as atividades de produção e interpretação de sentenças no ensino básico geralmente considerem apenas a sintaxe, deixando de lado a semântica. É sabido ainda que, em muitas situações, os conhecimentos trabalhados em sala de aula são articulados sem reflexão e com poucas discussões (VIEIRA, 2018). Para fazer frente a isso, a proposta é ver o aluno como o protagonista do seu próprio conhecimento, capaz de refletir sobre um fenômeno linguístico, de descrever e sistematizar em sala de aula as regras que regem sua produção linguística, como um pesquisador de fato (BASSO; OLIVEIRA, 2012). Como dizem esses autores:

\footnotetext{
${ }^{6}$ O Colégio e Curso Sonnart é uma instituição que tem como foco o ensino básico desde a educação infantil até o ensino médio. Além do ensino básico, uma preocupação constante desse colégio é a aprovação em concursos militares, em que vem apresentando muito êxito nos últimos anos. O colégio se localiza na Estrada do Galeão, 2925 - Portuguesa, Rio de Janeiro - RJ. 21931-582. Os interessados em conhecer o trabalho da escola também podem acessar http://sonnart.com.br/.
} 
[...] nossa proposta é usar o conhecimento linguístico que o aluno tem da sua língua - e é muito importante que seja a sua língua - para levá-lo a construir sua gramática, ensinando passo a passo como é o método científico: observar os dados, formular hipóteses, testá-las, refutá-las e assim construir a metalinguagem. Note que se trata de construir gramáticas; não é ensinar gramática, nem aplicar a gramática ao texto escrito. Esse exercício exige um olhar crítico e a consciência sobre diferentes regras, diferentes gramáticas. Ele permite que as questões de escrita ganhem uma nova perspectiva: entender a gramática da escrita. [...] Tal proposta requer que o português brasileiro finalmente entre na sala de aula. O grande desafio é que ela exige um professor muito bem preparado, um professor também curioso e que esteja sempre pesquisando. (BASSO; OLIVEIRA, 2012, p. 29-30)

Algumas hipóteses norteiam este estudo. Assumimos com Basso e Oliveira (2012) que os livros didáticos, por replicarem em certa medida as gramáticas tradicionais (GTs) ${ }^{7}$, não falam diretamente sobre a seleção semântica, tangenciando a questão ao classificar os predicadores como nominais, verbais, transitivos diretos etc. Ou seja, os materiais escolares não oferecem atividades que explorem a criatividade linguística por meio de uma relativa (des)obediência às propriedades semânticas impostas pelos predicadores das sentenças. Os materiais utilizados no ensino básico mantêm, tal como a GT, uma confusão de critérios sintáticos e semânticos para definirem o que seja argumento ou adjunto. A linguística pode ajudar os alunos a identificarem mais facilmente argumentos e adjuntos dentro de sentenças; o trabalho com sentenças anômalas é muito rico, levando à percepção fina de como operam os predicadores na seleção de argumentos. Embora os alunos não sejam expostos à nomenclatura técnica, nem venham fazendo na escola exercícios sobre o tema, assumimos que identificarão facilmente a anomalia semântica, compreendendo claramente os sentidos possíveis para sentenças anômalas.

Considerando que o estudo de pontos da gramática deve ser associado a uma produção discursiva em que sua presença seja natural (SCHNEUWLY; DOLZ-MESTRE, $1999^{8}$ ), optamos por apresentar memes, por esse gênero combinar uma imagem e um texto muito curto, limitado a uma sentença (geralmente anômala). Os memes podem ser assim caracterizados:

(a) construção composicional - os memes "padrão" costumam ser compostos por uma imagem e uma gíria ou bordão; normalmente, os

\footnotetext{
${ }^{7}[\ldots]$ a contar pela análise do material didático de ensino médio e fundamental indicado pelo MEC, o que se faz é manter em larga medida o ensino da Gramática Tradicional, reconhecendo a importância de se trabalhar com alguns aspectos do texto e do discurso, sem praticamente nenhuma incursão pela ciência da linguagem. (BASSO; OLIVEIRA, 2012, p. 22).

${ }^{8}$ Os autores defendem que o gênero seja sempre utilizado como meio de articulação entre as práticas sociais e os objetos escolares, sobretudo no domínio do ensino da produção de textos, quer sejam orais, quer escritos.
} 
recursos verbais são colocados sobre a imagem (em cima e embaixo) e não são necessariamente relacionados com o item visual; (b) conteúdo (temático) - geralmente é uma reação, crítica ou comentário sobre algum acontecimento, que pode ser expressado pela imagem e/ou pela frase utilizada; (c) estilo verbal - a mensagem é bem curta, escrita em linguagem informal. (GUERRA; BOTTA 2018, p. 1869)

De acordo com Cani (2019), um meme é a confluência de diferentes modalidades - texto escrito e imagem -, constituindo um discurso "onipresente em ambientes digitais como Facebook, Instagram, Whatsapp e Twitter" (CANI, 2019, p. 252). Por serem esses espaços frequentemente pontos de encontro de nossos jovens, supomos grande familiaridade dos alunos com o gênero, que permanece, não obstante, praticamente inexplorado nos livros didáticos.

Os memes provocam estranheza (explorando sentenças anômalas) com o propósito de produzir humor. Em especial, para a nossa proposta de sequências didáticas, a vantagem dos memes é que a imagem de fundo muito provavelmente vai orientar a interpretação da mensagem linguística, privilegiando uma interpretação inusitada da sentença anômala, em detrimento de outras leituras.

O artigo se organiza da seguinte forma: primeiramente, revisitaremos o conceito de $s$-seleção e de sentenças anômalas, em seguida, levantaremos a proposta de irmos a um livro didático, investigar, de forma meramente ilustrativa, o tratamento dado a esse fenômeno. Não temos a pretensão de esgotar o assunto, já que não examinaremos todas as obras similares. Em uma outra seção, analisaremos a intuição dos alunos quanto ao fenômeno investigado, acessada por meio de entrevistas. E, por fim, apresentaremos uma proposta de sequência didática/plano de aula que contemple o ensino no ensino básico, a fim de que a prática possa ser replicada, com ou sem adaptações, por outros educadores.

\section{A seleção semântica nos Estudos Linguísticos}

Nesta seção, discutiremos as vantagens de dar espaço na escola para atividades que abordam fenômenos como seleção semântica e anomalia semântica.

Segundo Quadros e Mendes (2018), a s-seleção pode ser compreendida como uma imposição do predicador, que envolve o exercício de certos papéis temáticos e propriedades que o referente do argumento deve apresentar ao entrar na grade argumental desse predicador. As autoras nos mostram que essas duas noções "dizem 
respeito à interface sintaxe-semântica" (QUADROS; MENDES 2018, p. 19). Para fins de ilustração, podemos examinar o predicado "dizer". Para que um predicado se torne saturado, é necessário verificar sua valência - o número de lacunas que um predicado possui - e preencher com argumentos adequados tantas quantas sejam as lacunas que esse predicado apresentar inicialmente, para que, juntos, predicado e argumento formem uma expressão complexa saturada, expressando um pensamento completo. 'Dizer" é um predicador que, saturado e com sentido completo, tem dois argumentos, ambos da categoria nominal: alguém diz algo. No entanto, imaginemos o exemplo em (1), que, apesar de obedecer às regras de boa formação sintática, causa certa estranheza:

1. \# A cadeira disse a verdade.

A peculiaridade do exemplo (1) decorre do não-atendimento às exigências semânticas do predicador pelo argumento externo: aquele que diz algo tem de ter voz e cérebro, sendo capaz de usar a linguagem para transmitir informações. A estranheza de (1) vem do fato de a cadeira não ter tais propriedades semânticas.

Assim como "dizer", "morar" também é um predicado com valência dois: para que uma sentença nucleada por esse predicado tenha significado completo, são necessários dois argumentos com certas propriedades semânticas. Vejamos os exemplos a seguir (23):

2. Davi mora na Ilha do Governador.

3. \#Davi mora no chocolate.

Nos exemplos (2) e (3), temos o mesmo predicado, com valência dois, recebendo dois argumentos. Entretanto, percebemos uma diferença no que tange à compreensão das sentenças. A sentença (2) é claramente aceitável, pois as exigências semânticas estão satisfeitas: o argumento em posição de sujeito, "Davi", é um ser humano, podendo residir num bairro, e "Ilha do Governador" é o nome de um lugar em que se pode morar. Por outro lado, isso não acontece com a sentença em (3), pois "chocolate" é um alimento e não um lugar passível de ser habitado. Temos aí um exemplo de violação da seleção semântica. Isso indica que a sentença (3) não apresenta um sentido usual, da linguagem cotidiana; mas ela pode ser "salva" ou "resgatada" num contexto muito controlado, que ressalte certa interpretação possível para ela. Por exemplo, a letra da canção Mora na filosofia, de autoria de Monsueto Menezes e Arnaldo Passos, de 1955, regravada em 1970, diz: "Mora na filosofia / Pra que rimar/Amor e dor", em que "morar" (em algo) é 
uma gíria que significa "atente para", "entenda sobre"; interpretando (3) no sentido dessa gíria, a sentença significa que Davi precisa entender ou já entende muito de chocolate.

Quando as propriedades semânticas do predicado são desrespeitadas, de acordo com Cançado (2008, p. 51), estamos diante do fenômeno de "anomalia semântica". Segundo a autora, a estrutura argumental mostra a estreita relação entre sintaxe e semântica. Como vimos, não basta satisfazer a valência do predicado; há que observar as propriedades semântico-lexicais. Chomsky (1981) defendia que a representação lexical das categorias incorpora as exigências semânticas feitas a seus argumentos.

Destacamos o fato de uma sentença com violação semântica ainda é interpretável, numa visão poética, metafórica, fugindo da literalidade convencional, do dia a dia. E essa ruptura com o sentido comum, normal, convencional, identificado com a observação da seleção semântica daquele predicado em sentenças bem cotidianas, mais frequentes, produz efeitos de sentido especiais, inusitados, afeitos a um uso literário, humorístico, irônico ou idiomático da linguagem. Não só as sentenças anômalas podem ter seu propósito comunicativo atendido, como podem, ainda, ser mais expressivas que as nãoanômalas, exatamente por explorarem os limites da boa formação, colocando a estranheza a serviço da formação de um sentido novo.

\section{A seleção semântica na escola}

Apoiados na ideia de que o aluno participe ativamente da construção de seu saber no processo de ensino (BASSO; OLIVEIRA, 2012), pretendemos explorar, em conexão com um aspecto da gramática da língua materna, uma prática discursiva contemporânea, o meme. A partir de nossa atuação docente, percebemos a necessidade de se criar o espaço para um trabalho linguístico reflexivo e crítico na sala de aula, que comporte temas como o aqui levantado, a seleção semântica e sua contraparte, a anomalia semântica. Os exercícios propostos têm o objetivo de servirem de ponta pé inicial para um diálogo entre os educadores interessados em novas abordagens para as aulas de língua portuguesa.

Veremos exemplos do gênero meme, em destaque por viralizarem pela internet. De acordo com Horta (2015), o meme emerge como uma das práticas comunicacionais na $w e b$, unindo o texto verbal e o texto não-verbal para produzir sua mensagem. Horta 
(2015) aponta que os memes tipicamente provocam riso. Para produzir efeitos de humor, e dado o caráter informal e descontraído da linguagem selecionada, um texto nesse gênero frequente e intencionalmente faz uso de sentenças anômalas. O nosso foco está na interpretação de sentenças anômalas, verificando os sentidos privilegiados pela imagem, nesse tipo de texto. A imagem do meme vai induzir a uma das interpretações possíveis para a sentença anômala ali presente, criando efeitos humorísticos.

Embora hoje exista um corpo de conhecimentos sólido no âmbito da linguística sobre a anomalia e a seleção semântica, a ponto de o tema já ter sido incorporado a obras destinas a disciplinas de semântica na graduação (tais como (CANÇADO, 2003, 2008; OLIVEIRA, 2012; QUADROS; MENDES, 2018), os livros didáticos de ensino fundamental e médio ainda não tratam dessa temática, que continua sem espaço para sua sistematização e/ou discussão em sala de aula. Quando muito, os livros didáticos de ensino fundamental e médio abordam o tema correlato da c-seleção, ou seleção categorial, falando sobre o número de argumentos requerido pelo predicador e sobre a categoria desses argumentos, principalmente ao falarem de transitividade verbal. Em geral, a abordagem se resume à apresentação de listas: listas de verbos sem sujeito, listas de verbo sem complemento, listas de verbos que exigem complemento direto ou complemento direto e indireto etc. Não se discute como os predicadores selecionam propriedades semânticas de seus argumentos. Além desse silêncio sobre a s-seleção, via de regra, se existe alguma abordagem quanto ao número de argumentos pedido por cada predicador verbal, a categoria deles, se oracional ou em forma de sintagma nominal, recebe bem menos espaço. Isso pode ser constatado no exame de alguns livros didáticos também adotados pela escola em que realizamos as atividades que reportamos neste artigo (PASCHOALIN; SPADOTO; 2019; PESTANA, 2013). O exame dessa mostra reforça que, de fato, não tem havido espaço no ensino o aspecto da seleção semântica. Nas poucas vezes em que os materiais didáticos trazem textos com a presença de anomalias, não as destacam, nem exploram os efeitos poéticos ou humorísticos ligados à quebra da $s$-seleção, perdendo a oportunidade de aproveitar um ensejo propício a essas discussões.

Não podemos deixar de lembrar, neste ponto, que a GT emprega uma semântica nocional, provocando confusão entre aspectos sintáticos e semânticos, como já foi apontado por diversos linguistas (DUARTE, 2007; VIEIRA; BRANDÃO, 2007). As recorrentes definições de advérbio, por exemplo, como palavra que significa tempo ou 
lugar, levam o aluno a classificar erroneamente "lá" como um advérbio de lugar em sentenças como "Lá é ótimo para se morar", quando nesse exemplo "lá" é argumento do predicador (é o lugar do qual se afirma ser ótimo para morar) e exerce a função sintática de sujeito. Da mesma forma, se dependerem do conteúdo das obras de GT e dos livros didáticos, os alunos do fundamental e do médio não terão base para analisar a semântica das sentenças nem para entender como são gerados efeitos de sentido pelo atendimento ou não à seleção semântica. Felizmente, a seleção semântica faz parte do conhecimento inato do falante de português do Brasil (PB) sobre a gramática da sua língua materna, facultando-lhe saber intuitivamente aquilo que não é tratado na escola.

Um desavisado que percebesse a ausência de qualquer exposição, mínima que seja, sobre a seleção semântica, nos materiais didáticos, poderia concluir que a escola considera que a boa formação das sentenças depende apenas de se observar o número de argumentos exigidos pelo verbo. Afinal, se o livro não incluiu certo tema, deve ser porque não é nada importante. Porém, como discutido na seção anterior, para se comunicar com eficácia, o falante, cotidianamente, precisa observar a seleção semântica; quando ela não é observada, interpretações pouco usuais emergem.

Para além da já comentada e famosa ineficácia das definições e critérios de classificação nocionais presentes nas GTs e nos livros didáticos, há um outro ponto importante: é preciso ser criterioso na seleção dos textos que vão rechear os livros didáticos. Como aponta Vieira (2018), cabe trazer aos alunos a realidade comunicativa e os dados de experiência que eles conhecem, para, assim, partindo do que já sabem, trabalhar melhor os aspectos gramaticais em aula. A escolha dos memes para as nossas atividades se coaduna com o ponto de vista preconizado pela autora. Por se tratar de um gênero do repertório dos alunos, seu emprego em atividades escolares é um facilitador para a abordagem de temas gramaticais.

Já que queremos avaliar uma questão gramatical do texto, é interessante levarmos em consideração o que Antunes (2017) aponta: a concepção de língua e linguagem adotada pelo professor em sala de aula se refletirá na sua prática de docência, tanto na escolha dos textos quanto na maneira pela qual as questões linguísticas serão trabalhadas. A obra citada traz uma concepção de língua e linguagem interacionista, propondo que o aluno assuma o protagonismo da comunicação, participando dos propósitos textuais, refletindo e pensando sobre as questões gramaticais. 
Para averiguar, como amostragem, a existência ou não de memes e de abordagens sobre o tema da seleção semântica em livros didáticos, investigamos a obra "Araribá Plus: Português" - um livro destinado ao 70 ano do ensino fundamental. Nossa escolha, para amostragem, recaiu sobre esse o livro por ele ser adotado na escola em que as atividades por nós propostas foram realizadas. Tendo em mãos esse material concreto, buscamos alguma menção ao assunto em capítulos sobre a transitividade verbal, porque, como foi defendido, a esse tema geralmente se vincula, indiretamente, como subtema, a seleção semântica. Avaliaremos aqui o tratamento dado à seleção semântica nessa obra, de Mônica Jacintho.

O livro é dividido em 8 unidades. Cada unidade dispõe dos subitens: imagem de abertura, leitura, estudo da língua, questões da língua, leitura e produção de texto e atitudes para a vida. Para os propósitos deste trabalho, nos limitamos ao subitem "Estudo da língua: análise e reflexão", presente na unidade 6 . Ali, a relação entre predicador e argumentos é assim definida:

A propriedade que os verbos de ação têm de exigir ou não complemento denomina-se transitividade verbal. $O$ verbo de ação que não precisa de complemento para compreensão da mensagem da oração é chamado de verbo intransitivo (VI). Aquele que precisa de um ou mais complementos para que a mensagem seja compreendida é chamado de verbo transitivo (VT). Uma sequência só é considerada complemento de um verbo de ação se for necessária para a compreensão do sentido desse verbo no contexto da mensagem". (JACINTHO, 2018, p. 219)

O fragmento supracitado aborda a transitividade verbal em verbos de ação, ponto facilmente relacionável com as questões de seleção categorial e de seleção semântica, mas esse espaço propício não foi aproveitado. Caberá ao professor que usa o livro traçar uma linha que permita a distinção entre argumentos e adjuntos. O trecho do livro didático reproduzido anteriormente é o fragmento que mais se aproxima de tangenciar a noção de seleção semântica. Assim, apesar de o livro didático estar comprometido com uma visão interacional da linguagem, o tratamento dado nele à transitividade verbal aparece ainda desvinculado do uso da língua em sociedade, bem como completamente dissociado dos saberes que os alunos trazem consigo sobre sua língua materna ao ingressarem na escola. As atividades para os alunos aparecem nele na forma de propostas de exercícios mecânicos de classificação de verbos de ação em intransitivos, transitivos diretos e transitivos indiretos, conforme o número de argumentos de cada um. Estamos afirmando que o que acaba sendo feito é um exercício mecânico porque o aluno 
precisa dar conta da classificação de verbos em intransitivo, transitivo direto e transitivo indireto sem receber qualquer auxílio sobre táticas de como reconhecer qual é o predicador e quais são seus argumentos dentro de um sintagma verbal. Supõe-se que o aluno já seja capaz de distinguir predicador de argumento a essa altura. Mas essa expectativa é falsa. Chamar a atenção dos alunos para a satisfação da seleção semântica do verbo por seus argumentos tornaria o reconhecimento da grade argumental muito mais fácil. Se um livro tão comprometido com a visão interacionista da linguagem aborda assim o tema, não podemos esperar que obras mais tradicionais, mais presas aos pontos da GT, façam melhor que isso. Foi a necessidade de repensar como trabalhar esses tópicos no ensino que nos motivou a propor sequências didáticas de atividades que explorem a intuição dos alunos quanto à seleção semântica.

Como ponto de partida, consideramos que, apesar de o fenômeno da seleção semântica e os efeitos das anomalias dentro dos textos não ser tratado nos materiais escolares, os alunos do ensino regular são falantes nativos da língua, e, portanto, mesmo enquanto pequenos, já são capazes de perceber os efeitos causados pelo desrespeito à s-seleção, por algum motivo, nas mais diversas situações comunicativas. Acreditamos que, se partirmos daquilo que eles já sabem, ficará muito mais fácil construir com eles um novo conhecimento sobre sua gramática. Na próxima seção, discutimos uma atividade dirigida para a explicitação desse conhecimento inato e inconsciente do falante sobre sua língua materna.

\section{Uma investigação exploratória sobre a intuição de alunos do fundamental quanto à seleção semântica}

Como forma de contribuir para o aproveitamento em sala de aula do conhecimento linguístico sobre a relação entre gramática e significado na nossa língua materna, presente em estudos de semântica formal, particularmente no que tange à seleção semântica, propomos o exame dos efeitos de sentido produzidos pela anomalia em memes, gênero que, para estabelecer a ironia ou o humor num jogo entre certa imagem e determinado texto linguístico, usualmente se vale de sentenças anômalas. Buscamos inicialmente acessar o conhecimento trazido de casa pelos alunos, acreditando que, por serem fluentes em seu vernáculo, eles já apresentam uma percepção clara das propriedades sintáticas e semânticas de um predicado na sua língua materna. 
Acreditamos poder acessar com esse jogo interpretativo as regras inconscientes de boa formação de uma língua específica, no caso, o português falado no Brasil, utilizando a compreensão dos memes como uma janela para vermos que efeitos de sentido podem surgir a quebra da seleção semântica. Assumimos que a percepção da não-satisfação da seleção semântica em contextos de uso desviantes depende da identificação plena das exigências semânticas impostas pelos predicadores sobre seus argumentos em situações convencionais, no uso cotidiano da linguagem.

Para investigarmos a intuição dos alunos sobre o fenômeno, selecionamos alguns memes que continham sentenças anômalas. Apresentamos aos alunos de uma turma sete memes $^{9}$. Essa investigação tomou a forma de uma atividade didático-pedagógica realizada em sala de aula pelo professor regente de língua portuguesa, como parte do desenvolvimento da matéria da disciplina. Participaram da atividade sete crianças de uma mesma turma, com idade entre 12 e 14 anos $^{10}$.

Decidimos realizar essa pesquisa por meio de atividade interativa individual, em formato de entrevista, para que as respostas dos demais alunos não interferissem no que cada um viesse a dizer. Assim, ficaríamos mais perto da compreensão espontânea de cada participante sobre o sentido da sentença anômala. Foi apresentado um conjunto de três memes a cada participante. O participante foi incentivado a explicitar seu entendimento da parte linguística do meme, no contexto da imagem a que a sentença vinha atrelada. Numa segunda etapa, era debatido com o aluno que caminhos levavam à interpretação obtida, e de que mecanismos o autor se valeu para alcançar o efeito de humor ou ironia próprio desse gênero textual.

O primeiro meme apresentado propositalmente não dispunha de imagem de fundo. A ideia que presidiu à escolha desse texto em particular para o início das atividades era a de verificar se a expressão "eu beijo o problema" causaria estranhamento, mesmo sem nenhum contexto imagético dirigindo a elucidação do sentido. 0 meme apresentado de forma individual aos alunos foi o seguinte:

\footnotetext{
${ }^{9}$ Para a discussão no presente artigo, fizemos uma seleção de parte do conjunto utilizado na atividade.

10 Agradecemos aos alunos participantes (e a seus responsáveis, já que se trata de menores), que consentiram explícita e livremente em participar dessas atividades, como parte de sua rotina escolar, estando cientes e de acordo com o fato de que os resultados gerais seriam publicados em forma de artigo, com a devida preservação da identidade dos alunos. A direção da escola, a quem agradecemos, também aprovou a publicação de um artigo sobre as técnicas pedagógicas empregadas.
} 
Figura 1 - Meme "beijo o problema"

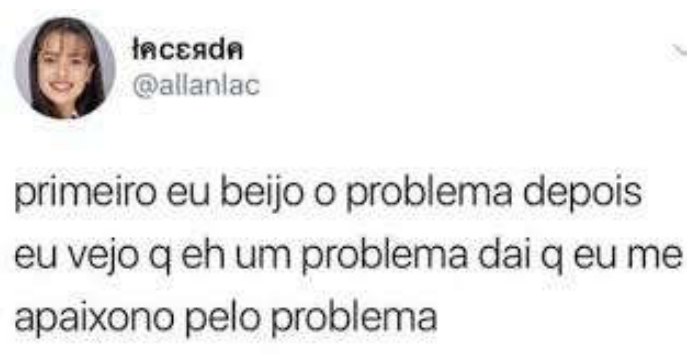

Fonte: Memes... (2018).

Em "eu beijo o problema", temos uma sentença anômala, pois o predicado "beijar" exige de seu argumento externo, com papel temático de agente, um SN, os traços semânticos: [+animado], ter poder de decisão, estar imerso em cultura, ter lábios capazes de formar um beijo e ter compreensão desse gesto como manifestação de afeto; do argumento interno, um SN com papel temático de tema, "beijar" exige que seja algo concreto, com uma superfície física passível de ser beijada. Na sentença dada, o argumento externo atende à s-seleção do predicador, mas o argumento interno não, pois, sendo algo abstrato, não apresenta uma superfície concreta que possa receber a compressão dos lábios de quem beija.

Vamos aos comentários dos alunos: "A gente beija pessoas", disse um; "Depende, eu acho que a gente beija pessoa. A gente não beija um problema, é normal a gente beijar pessoa. As pessoas beijam pra mostrar que gostam uma das outras", disse outro; a frase é esquisita porque "o problema não é uma pessoa", disse um terceiro. Por essas respostas, notamos que os alunos dominam a s-seleção desse predicador. Embora eles não conheçam os nomes técnicos empregados, nas teorias linguísticas, para descrever e explicar a relação entre os predicados e os argumentos, ficou claro que eles percebem que o humor nos memes é um produto justamente da quebra da construção rotineira da sentença, do desrespeito à seleção semântica, já que, em suas respostas, os alunos encaixaram com o predicado sempre um argumento em acordo com a s-seleção de "beijar", contrapondo à sentença apresentada uma versão dela em que as exigências semânticas do predicador são inteiramente satisfeitas.

Um segundo meme apresentado aos alunos é reproduzido na figura 2, a seguir: 
Figura 2 - Meme "servir o homem"

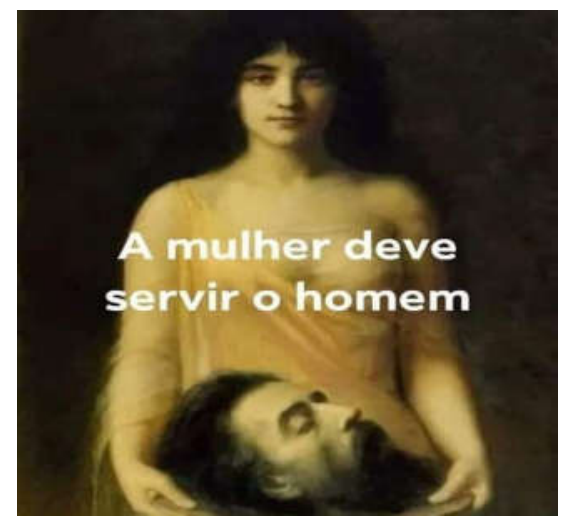

Fonte: Thaila... (2019).

Fica evidente, nesse texto, a ironia estabelecida pelo jogo entre a sentença e a imagem. Em "a mulher deve servir o homem", o predicado "(deve) servir" s-seleciona três argumentos: quem serve, aquilo que é servido e, opcionalmente, a quem é servido. Os dois argumentos indispensáveis, quem serve e aquilo que é servido, têm de ser categorialmente sintagmas nominais (SNs); o terceiro argumento, o opcional, normativamente falando, ou seja, segundo as regras da gramática normativa, deveria assumir categorialmente a forma de um sintagma preposicionado (SP): alguém serve alguma coisa a alguém, ou para alguém. Do ponto de vista das propriedades semânticas, na leitura-padrão, literal, cotidiana de sentenças com esse predicador, tanto $o$ argumento externo quanto o opcional têm de apresentar propriedades de ser mais animado, de ser consciente, imerso em uma cultura com serviços, enquanto que o argumento interno indispensável, aquilo que é servido, tem de ser algo não-animado, inerte, inconsciente: matéria da qual aquele que é servido possa se alimentar. Essas exigências semânticas seriam prontamente atendidas numa sentença como "a mulher deve servir as refeições ao homem", que segue não só a regência-padrão, mas também obedece à s-seleção do predicador e, na interpretação não-específica, genérica, dos SNs "a mulher" e de "o homem", tem um viés inequivocamente machista, estabelecendo como dever das representantes do sexo feminino colocarem-se a serviço dos representantes do sexo masculino, satisfazendo seus apetites e servindo à mesa em que estes os saciam. Porém, a sentença presente no meme traz apenas dois argumentos, ambos portadores das propriedades semânticas de ser animado, consciente e imerso em uma cultura com serviços. Uma das interpretações possíveis para a sentença presente no meme, então, considerando ter havido obediência à s-seleção, é a de que foi omitido o argumento interno essencial (aquilo que é servido), dado que nenhuma dos dois argumentos 
realizados é convencionalmente comestível. Assumindo uma regência não-padrão para o argumento que representa quem é servido, a preposição poderia ser dispensada. Teríamos então a leitura de que as mulheres devem servir aos homens (o que quer que haja para ser servido nas situações relevantes). Essa é a leitura com posição ideológica machista, que coloca a mulher como submissa e o homem como proeminente. Mas não é isso que a imagem do meme ilustra. Temos como pano de fundo uma representação pictórica de Salomé servindo a cabeça de São João Batista, numa bandeja de prata. 0 único modo de a sentença descrever a situação ilustrada pela imagem é num entendimento linguístico alternativo, em que se assume que os dois argumentos presentes representam a pessoa que serve e o alimento que é servido, que são os dois argumentos essenciais à saturação do predicador "servir", e que estão em acordo com a c-seleção da regência padrão; por outro lado, essa leitura coloca como o alimento servido algo inusitado e inesperado, pois nossa cultura não acata o uso de carne humana na nossa alimentação, fator determinante para que, convencionalmente, seja exigido do argumento interno representando o alimento que tenha uma referência portadora do traço [-humano]. Enfim, a violação da s-seleção é necessária para que o significado da sentença e o da imagem convirjam.

O leitor do meme, num primeiro momento, tende a optar por uma entre duas interpretações salientes para a sentença apresentada. Numa, a seleção semântica imposta aos argumentos realizados é satisfeita, porém, em contrapartida, o argumento interno que está presente não é o essencial, mas o facultativo, estando o essencial omitido; além disso, pela normatividade, esperaríamos que esse argumento, "o homem", viesse em uma estrutura de SP. Na outra leitura saliente, os argumentos internos essenciais são os realizados, e sua estrutura não fere a normatividade, porém o argumento interno essencial desrespeita a s-seleção convencional, ao trazer o traço [+ humano]. Essa última leitura gera um significado tabu na nossa cultura, aludindo ao consumo de carne humana. A imagem favorece exatamente essa interpretação, em detrimento da alternativa. A interpretação saliente alternativa, que foi descrita anteriormente, está em acordo com a ideologia sub-reptícia de uma sociedade machista, em que os homens subjugam a mulheres. A compreensão total do meme requer a percepção de ambas as interpretações viáveis para sua única sentença, contrapondo um discurso ao outro, para que assim o meme veicule uma voz contrária ao discurso machista, que diz: substitua o serviço feminino que deve ser prestado ao homem de 
acordo com certos pensamentos por uma libertação do oprimido que se alevanta, vence e elimina seu opressor. Esse conteúdo verbal complexo é mais adulto, lidando com uma agenda feminista, e é apoiado pela imagem, em que a mulher, trazendo uma cabeça de homem servida na bandeja, mostra o resultado de uma espécie de insubordinação vingativa.

Essa atividade é um exemplo de escolha infeliz de material, pois a temática da subordinação feminina ao sexo oposto está longe de ser um questionamento vivido de perto por crianças de 12 a 14 anos, sobretudo pelas do sexo masculino. Talvez por isso mesmo, constatamos que, em geral, os alunos dessa faixa etária tiveram um pouco de dificuldade na interpretação desse texto. Não obstante, alguns foram capazes de enxergar os jogos sintático-semânticos presentes no texto, como indicam os comentários: "Ah, tá brincando com um negócio que a mulher deve sempre ficar servindo bebida pro homem. Aí tá brincando que a mulher tá servindo a cabeça do homem. De zoeira. Tá tendo ironia". "Servir o homem, não sei explicar, a gente não espera que o homem seja servidd", disse um participante. Outro aluno comentou: "Que eles tão falando uma piada, era pra ser uma piada. Que uma mulher tem que fazer tudo pro homem sem questionar. Acho que tinha que tá ao homem, porque taria dando pro homem e não o homem". Um terceiro disse que o meme era estranho "porque é literalmente uma mulher servindo o homem. Isso não é, tipo não pode ser normal, porque não pode servir o homem, ele não é comida." As falas recolhidas evidenciam a capacidade inata dos falantes quanto ao fenômeno em análise e deixam claro o que já havia sido antecipado como hipótese: que, embora os alunos desconheçam os nomes técnicos para a quebra dessa expectativa relacionada à anomalia, eles captam esses mecanismos linguísticos facilmente.

Outro meme apresentado aos alunos foi o seguinte:

Figura 3 - Meme "tomar distância"

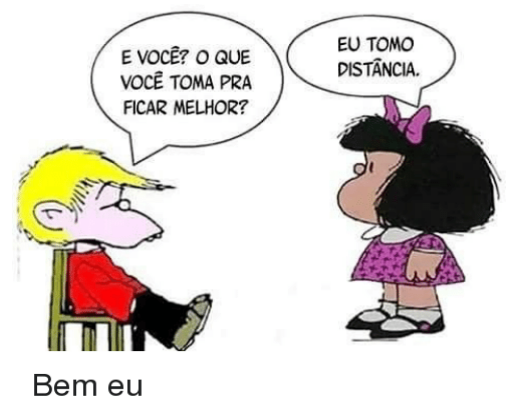

Fonte: Pinterest (2019). 
O texto da figura (3) também traz uma certa dificuldade para alunos dessa faixa etária, nem tanto por conta do leque de significados que o predicado "toma" pode assumir: "tomar sorvete", "tomar injeção", "tomar distância", "tomar o ônibus", "tomar providências" etc., mas mais especialmente (e felizmente) por conta da falta de experiência de mundo relacionando o consumo de medicação ou drogas com a finalidade de ganhar resiliência às pressões psicológicas do cotidiano. A situação invocada por falas como "o que você toma para aguentar a pressão, o stress?", no mundo adulto do trabalho, remete ao consumo de drogas para o sistema nervoso. Mas essa questão não se põe para o cotidiano das crianças. Assim mesmo, alguns dos alunos observaram, nos termos deles, que o argumento interno s-selecionado pelo predicado "toma" deve ter propriedade semântica [+ medicinal], tendo como potenciais referentes remédios por ingerir, ou na forma líquida ou em pílula, com a finalidade de produzir bem-estar. Isso fica evidenciado pela palavra "melhor" e pelas características do desenho: a criança sentada é uma criança cabisbaixa, sem disposição, desanimada. No entanto, ao repararmos na resposta da menina, vemos que o predicado "tomar" foi interpretado de uma forma diferente e não no sentido de "ingerir", mas com o sentido de assumir uma atitude de distanciamento moral ou psicológico. Temos então nesse meme a exploração da polissemia de "tomar", que, numa acepção, tem como argumento algo que possa ser ingerido e digerido, e, na outra, um nome denotador de certa atitude a ser interiorizada, assimilada (como em "tomar distância", "tomar jeito", "tomar tento", "tomar juízo", "tomar consciência" etc.). A ligação entre as duas falas (atendendo à Máxima da Relação, de Grice, que rege os diálogos, segundo o Princípio da Cooperação da teoria pragmática da conversação) só faz sentido se entendermos que, em vez de a menina tomar drogas para aguentar os problemas, ela se afasta de ambientes problemáticos para evitar ser negativamente afetada por eles. É solicitada a escolha da melhor entre duas atitudes alternativas para suavizar os efeitos de um ambiente negativo, ou de uma situação estressante indesejada: ou alterar artificialmente a própria psicofisiologia, ou sair fora (psicologicamente) do lugar de opressão. Apesar da dificuldade potencial representada pela temática adulta do meme, a julgar pelas falas dos alunos, alguns deles perceberam claramente as diferenças de sentido entre "tomar algo para relaxar/ suportar" (um anestésico, um calmante) e "tomar distância" (não ser alcançado pelos problemas). Uma das falas foi: "Tomar, ele quis dizer remédio, e ela quis dizer distância, porque tem pessoas que é melhor manter à distância. É a distância que causa humor, 
porque ela tá falando que é melhor manter distância das pessoas que fazem mal a ela". A fala reportada mostra claramente a percepção do que a personagem queria dizer naquele contexto e apresenta o mecanismo responsável por estabelecer o humor dentro do texto. Outro participante disse o seguinte: "Esse 'tomar' não tá no sentido de tomar, porque não dá para tomar distância, é um jeito de falar diferente". Nesse comentário, fica explícito que "tomar" assume significados diferentes, conforme a natureza semântica de seu argumento interno. Um terceiro comentário ouvido, mais sucinto, mas também revelador dessa intuição, foi: "Tem mais de um sentido esse verbo". Vemos, assim, que os falantes percebem os efeitos da seleção semântica e da anomalia, mesmo que não sejam expostos à sistematização desses fenômenos rotineiramente na escola.

Procuramos, nesta seção, mostrar como o gênero meme é particularmente interessante para uma estimulação da explicitação de intuições do falante sobre a seleção semântica. Dadas a popularização e a universalidade do meme, que traz conteúdos dirigidos às mais diversas faixas etárias, ficou patente também a utilidade de selecionar criteriosamente materiais que tematizem situações mais apropriadas à vivência dos alunos dessa faixa etária particular. Esse é um ajuste que pretendemos fazer nas próximas vezes em que propusermos essas atividades. Tomados esses cuidados, acreditamos que as atividades renderão ainda mais. Na seção seguinte, trataremos de como dar sequência à extração dos conhecimentos intuitivos dos alunos sobre a seleção semântica.

\section{Proposta de elaboração e aplicação de uma sequência didática}

A partir do que foi discutido aqui, notamos que seleção semântica e anomalia são fenômenos que fazem parte da gramática inata dos falantes, embora esses conhecimentos não sejam tematizados ou sistematizados em sala. Entendendo a importância da seleção semântica e da anomalia para a produção de sentido dos textos, propomos aqui um plano de aula que inclua no ensino gramatical esses tópicos, como uma forma de aprimorar a compreensão textual dos alunos e refletir sobre os elementos usados para um determinado objetivo.

$\mathrm{O}$ plano de aula a seguir foi baseado na plataforma do $\mathrm{MEC}^{11}$. Entendemos que a estrutura do plano de aula disponibilizada pelo MEC procura seguir as diretrizes da Base

\footnotetext{
${ }^{11} \mathrm{Em}:$ https://plataformaintegrada.mec.gov.br/home\#
} 
Incorporando às sequências didáticas no ensino básico a análise de memes trazendo sentenças anômalas - em desobediência à seleção semântica

Nacional Comum Curricular (BNCC), sendo adotada por secretarias municipais e estaduais. Ademais, apoiamos o projeto político que embasa esse modelo.

Quadro 1 - Plano de aula

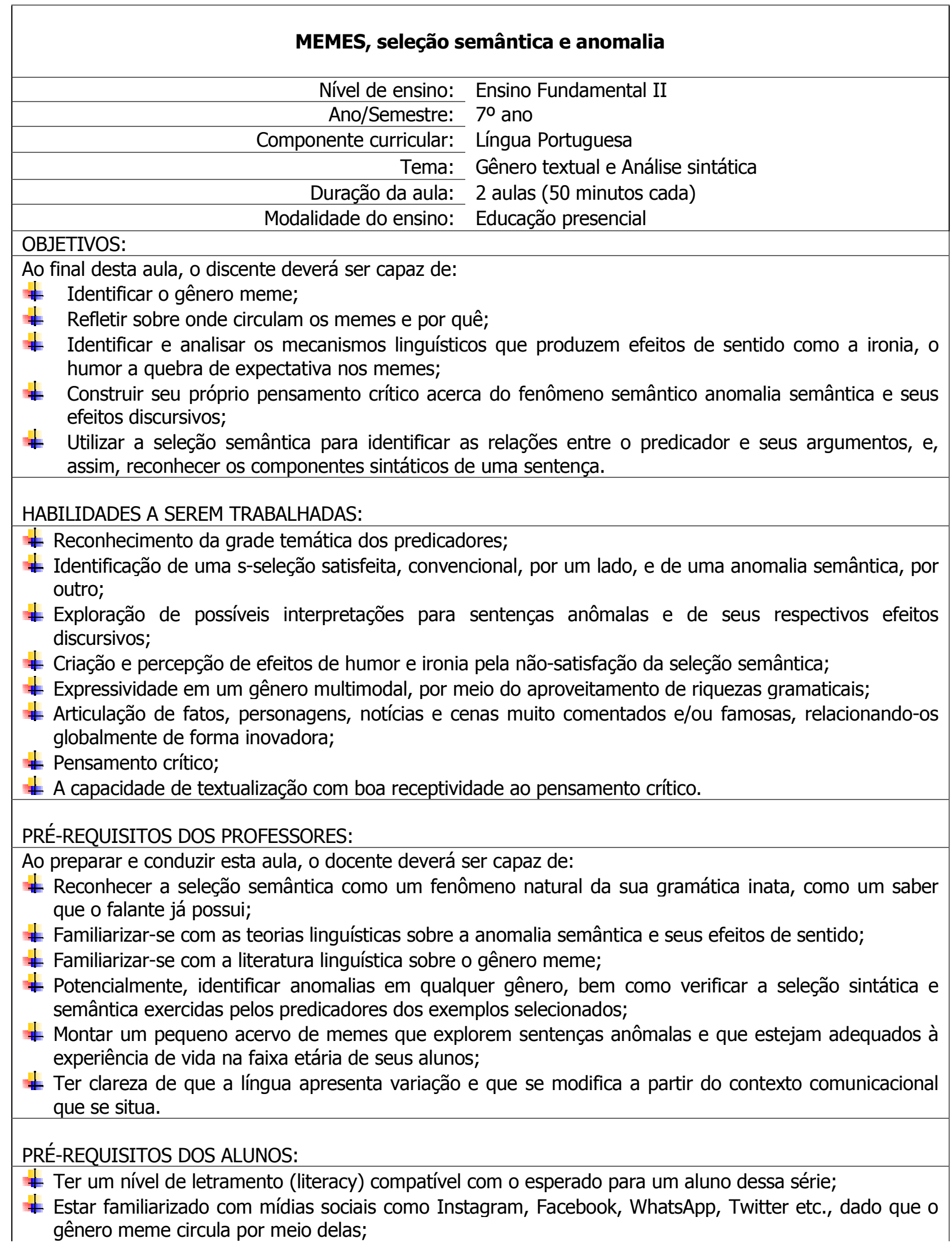


Franco, D. L.; Gomes, A. P. Q.

Ter sido instruído sobre os rótulos gramaticais usados na escola para identificar classes de palavras e funções sintáticas, ao nível dos conteúdos da série anterior;

\section{RECURSOS / MATERIAIS DE APOIO:}

t Memes selecionados;

- Apresentação dos memes em slides ou em forma de cartaz;

* Quadro para sistematização do conteúdo.

\# Gerador de memes: https://www.gerarmemes.com.br

Museu de memes: http://www.museudememes.com.br

\section{JUSTIFICATIVA:}

\# Os jovens de hoje frequentemente navegam por textos multimodais, nas mídias sociais, mas raramente encontram espaço na escola para refletir sobre eles;

\# A interpretação de gêneros textuais significativos para os alunos é bem mais estimulante para uma troca colaborativa do que a interpretação de gêneros escolares, artificiais, cuja circulação permanece restrita à sala de aula;

\& O gênero meme sintetiza, de forma multimodal, informações diversas acerca do momento históricocultural vivido pelos alunos, bem como veicula um posicionamento a respeito dos fatos;

* A natureza da conexão, no meme, entre, de um lado, uma única sentença, frequentemente anômala, e, de outro, uma imagem que prioriza um sentido para ela, faz desse gênero um terreno fértil para a sistematização dos conhecimentos intuitivos sobre a seleção-semântica;

\# A sistematização dos conhecimentos sobre a grade temática de um predicador e a elaboração sobre ele facilitam a análise de uma sentença, como sua divisão em sujeito, predicado e complemento, criando as condições para a construção de uma análise gramatical consistente;

\# A consciência sobre os efeitos de sentidos relacionados à anomalia semântica enriquece $o$ arsenal expressivo do aluno como produtor de textos

\section{METODOLOGIA:}

Como momento inicial, os alunos seriam expostos a alguns memes. Professor, deixe os alunos à vontade para falar sobre o que estão vendo, o que acham dos textos, para rirem e discutirem. Se for preciso algum incentivo ao debate, perguntar "qual é a graça?" pode ser um bom começo. Exemplo de memes:

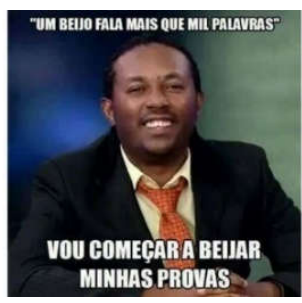

Nesse primeiro momento, o protagonismo deve ser dos alunos: os professores não devem explicar nada, apenas fazer a mediação do diálogo entre os alunos sobre o que estão achando sobre o texto. Num segundo momento, a partir de falas espontâneas dos alunos, a situação tematizada no meme, os efeitos de humor, de ironia, a crítica veiculada, os elementos estruturais desse texto etc. podem ser enfatizados pelo professor.

Em seguida, os alunos podem ser estimulados a encadear uma argumentação demonstrando que estamos diante do gênero meme, com o qual eles já estarão familiarizados por suas redes sociais. (Espera-se que essa prática textual comunicativa já seja compartilhada por todos eles.) A seguir, partindo das contribuições dos alunos, o professor pode sistematizar a caracterização desse gênero textual, salientando como que os memes são multimodais. Além da discussão da estrutura do texto, é válido debater sobre a construção da ironia, do humor e da crítica que marcam esse gênero textual. Esse é o momento propício para explorar as fontes semânticas de tais efeitos discursivos, pedindo interpretações possíveis para a sentença, e. depois, verificando como os alunos acham que cada uma se casa ou não com a contextualização dada pela imagem. A seguir, a estranheza ou quebra de expectativa do texto verbal, em si mesmo ou contra essa imagem de fundo, pode ser explorada. A partir das contribuições dos alunos, a seleção semântica pode ser explicitada, com o professor fornecendo outros exemplos da linguagem convencional, contrapondo sentenças em que a seleção é satisfeita a sentenças em que há anomalia, e perguntando aos alunos que interpretações as sentenças anômalas sancionam ou não. A fim de dar continuidade a essa etapa, o 
docente poderia discutir sobre a seleção de argumentos, explicando os aspectos de transitividade verbal e, depois dessa exposição de conteúdo, pedir aos alunos que classificassem esses predicadores quanto à transitividade verbal e levantassem um debate sobre por que esses predicados se classificam como transitivos diretos ou intransitivos. É natural que a maioria das respostas sigam a seleção categorial apenas, mas sua sistematização contribuirá para o debate a ser articulado mais à frente. Um dos questionamentos que pode ser levantado é: "Se as sentenças que nós lemos estão respeitando às regras da sintaxe, por que ainda assim essas sentenças provocam um efeito de riso em nós que estamos lendo?"

AVALIAÇÃO:

\# Os alunos podem pesquisar outros memes na internet que contenham sentenças anômalas; depois, eles podem discutir os efeitos de sentido produzidos pela anomalia e reconstruir essas sentenças, de modo que a seleção semântica do predicador seja satisfeita.

- Os alunos podem criar seus próprios memes com sentenças anômalas, usando um gerador de memes.

Os alunos podem, ainda, buscar sentenças anômalas em outros gêneros textuais, como em piadas, poemas, HQs etc.

Fonte: Os autores.

Embora, hoje em dia, os jovens estejam sempre navegando por diversos tipos de textos online, pouco se reflete em sala de aula sobre os textos a que estão sendo expostos em seu cotidiano. É importante trazer as situações comunicativas cotidianas para a sala de aula. Entendemos também que a construção do conhecimento se torna mais eficaz quando ocorre uma troca colaborativa (LEU et al., 2013). Promover a reflexão sobre o gênero meme é uma estratégia para situar os alunos no tempo histórico e cultural em que vivem. Além disso, sistematizar suas intuições sobre a seleção semântica e a anomalia vai ajudá-los não só a interpretar um meme, mas também a confiarem nas suas intuições sobre a grade argumental para construir sua análise linguística. Com isso, o professor terá um espaço propício para a discussão de seleção semântica e anomalia semântica. É fundamental que o docente, no exercício de seu papel de mediador das discussões, não se esqueça de deixar explícito que a satisfação da seleção semântica está ligada ao sentido literal e ao uso convencional das sentenças, e que a violação da seleção semântica cria efeitos especiais de sentido, afeitos à linguagem poética, ao idiomatismo, à ironia e ao humor. A prática de usar os conhecimentos linguísticos que os alunos já têm como recurso para se alcançar instrumentalmente uma análise linguística mais sofisticada, bem como para se obter maior expressividade na produção linguística se enquadra na teoria dos três eixos (VIEIRA, 2018), proporcionando um ensino de gramática reflexivo, textual e variacionista. Ademais, como defendido por Basso e Oliveira (2012), o aluno, nessa proposta, desempenha não um mero papel receptor, mas também faz o papel de um pesquisador em sala de aula. 


\section{Considerações Finais}

Neste trabalho, defendemos que certos conhecimentos - sobre seleção semântica e anomalia semântica - trazidos pela pesquisa linguísticos, já consensuais entre os pesquisadores da área, sejam aproveitados no ensino regular de língua materna. Acreditamos que construir o conhecimento sobre a língua em sala de aula, a partir do que conhecimento trazido de casa, ajuda a enraizar mais o domínio da gramática e refina a percepção intuitiva sobre a semântica das sentenças. Entendemos que os alunos disporão de mais uma ferramenta linguística para investigar a ironia, a crítica e o humor, dentro de textos como os memes. Além de poderem trabalhar com práticas sociais discursivas presentes na sua própria vida, e, portanto, mais significativas para eles, os alunos vão refletir sobre a semântica das sentenças em sua língua materna. Reconhecer a seleção semântica é um passo fundamental para a divisão dos componentes sintáticos da sentença em sujeito, predicado e complemento. A proposta que aqui disponibilizamos contribui para um ensino reflexivo de língua materna em sala de aula.

Como resultado da experiência de aplicação das atividades aqui descritas, medimos o seu alcance: os alunos participantes demonstraram, ao final, serem mais capazes de perceber as anomalias, além de terem sabido explorar sua influência no significado das sentenças, percebendo os efeitos de seu uso nos textos. Tendo em vista que o recurso da violação da seleção semântica dentro dos textos é muito presente para gerar um sentido incomum, com quebra do convencionalismo e/ou de expectativas, consideramos fundamental que esse fenômeno seja discutido no âmbito das salas de aula, minimamente na mesma proporção em que se discutem fenômenos como seleção categorial. O estudo sintático que trata de projeção de argumentos precisa ser mais desenvolvido, dado que há propriedades lexicais atuando tanto na boa formação sintática quanto na produção de sentido. Acreditamos que a consciência das propriedades semânticas selecionadas pelo predicador pode ajudar bastante na identificação do predicador sentencial e no reconhecimento de seus argumentos. Por isso, pensamos que este material avança, ao disponibilizar aos professores de ensino básico um plano de aula que proporcione aos seus alunos a chance de refletir sobre a gramática da própria língua, explorando os efeitos expressivos da seleção semântica dentro de memes. Esperamos que os educadores testem as sugestões e aperfeiçoem a proposta. 
Incorporando às sequências didáticas no ensino básico a análise de memes trazendo sentenças anômalas - em desobediência à seleção semântica

\section{Referências}

ANTUNES, Irandé. Muito além da gramática: por um ensino de línguas sem pedras no caminho. São Paulo: Parábola Editorial, 2017.

BASSO, Renato Miguel; OLIVEIRA, Roberta Pires. Feynman, a linguística e a curiosidade, revisitado. Matraga: estudos linguísticos e literários, Rio de Janeiro, v. 19, n. 30, p. 1340, 2012.

CAMPOS, Haroldo. Galáxias. São Paulo: Ex-Libris, 1984.

CANÇADO, Marcia. Manual de semântica: noções básicas e exercícios. Belo Horizonte: Editora UFMG, 2008.

CANÇADO, Marcia. Um estatuto teórico para os papéis temáticos. In: MULLER, Ana Lúcia; NEGRÃO, Esmeralda; FOLTRAN, Maria Jose (org.). Semântica formal. São Paulo: Editora Contexto, 2003. p. 95-124,

CANI, Josiane Brunetti. Multimodalidade e efeitos de sentido no gênero meme. Revista Periferia, Rio de Janeiro, v. 11, n. 2, p. 242-267, maio/ago. 2019.

CHOMSKY, Noam. Lectures on government and binding. Dordrecht: Foris, 1981.

DUARTE, Maria Eugenia Lamoglia. Termos da oração. In: Vieira, Sílvia Rodrigues; Brandão, Sílvia Figueiredo. (Orgs.) Ensino de gramática: descrição e uso. São Paulo: Contexto, 2007.

GUERRA, Christiane; BOTTA, Mariana Giacomini. O meme como gênero discursivo nativo do meio digital. Domínios de Lingu@gem, Uberlândia, v. 12, n. 3, p. 1859-1877, 2018.

HORTA, Natalia Botelho. O meme como linguagem da internet: uma perspectiva semiótica. 2015. Dissertação (Mestrado em Comunicação) - Universidade de Brasília, Brasília, 2015. Disponível em:

http://repositorio.unb.br/bitstream/10482/18420/1/2015_NataliaBotelhoHorta.pdf. Aceso em: 9. set. 2019 às $17 \mathrm{~h} 51 \mathrm{~min}$.

JACINTHO, Mônica Franco (ed.). Araribá Plus - português, 70 ano. 5. ed. São Paulo: Editora Moderna, 2018.

LEU, Donald J.; KINZER, Charles K.; COIRO, Julie; CASTEK, Jill; HENRY, Laurie A. Novas literacias: uma teoria de duplo nível da natureza mutável da alfabetização, instrução e avaliação. In: RUDDELL, Robert B.; UNRAU, Norman J. Theoretical models and processes of reading. Newark, DE: International Reading Association, 2013.

MEMES e gifs de engraçado. 2018. Disponível em:

https://pt.dopl3r.com/memes/engra\%C3\%A7ado/atallanlac-primeiro-eu-beijo-oproblema-depois-eu-vejo-q-eh-um-problema-dai-q-eu-me-apaixono-peloproblema/230744. Acesso em 18 dez. 2019.

OLIVEIRA, Roberta Pires. A linguística sem Chomsky e o método negativo. ReVEL, [S. L.], v. 8, n. $14,2010$. 
OLIVEIRA, Roberta Pires. Semântica formal: uma breve introdução. Campinas, SP: Mercado de Letras, 2012.

PASCHOALIN, Maria Aparecida; SPADOTO, Neuza Terezinha. Gramática: teoria e atividades. Londrina: Editora FTD, 2019.

PESTANA, Fernando. A gramática dos concursos públicos. São Paulo, SP: Editora Método, 2013.

PINTEREST. Disponível em: https://br.pinterest.com/pin/859061697651351377/. Acesso em: 22 dez. 2019.

QUADROS, Ana Gomes; MENDES, Luciana Sanchez. Para conhecer semântica. São Paulo: Contexto, 2018.

SCHNEUWLY, Bernard; DOLZ-MESTRE, Joaquim. Os gêneros escolares. Das práticas de linguagem aos objetos de ensino. Revista Brasileira de Educação, Rio de Janeiro, n. 11, 1999.

THAILA Ayala faz post polêmico na web e internautas repercutem negativamente. $G Q$, Rio de Janeiro, 26 abr. 2019.Disponível em: https://gq.globo.com/Musa/noticia/2019/04/thaila-ayala-faz-post-feminista-na-web-einternautas-repercutem-negativamente.html. Acesso em: 18 dez. 2019.

VIEIRA, Silvia Rodrigues. Três eixos para o ensino de gramática. In: VIEIRA, Silvia Rodrigues (org.). Gramática, variação e ensino: diagnose e propostas pedagógicas. São Paulo: Blucher, 2018. p. $47-60$.

VIEIRA, Silvia Rodrigues; BRANDÃO, Silvia Figueiredo (org.). Ensino de gramática: descrição e uso. São Paulo: Contexto, 2007. 